\title{
Pulmonary Shunt Fraction Measurement Compared to Contrast Echocardiography in Hereditary Haemorrhagic Telangiectasia Patients: Time to Abandon the $100 \%$ Oxygen Method?
}

\author{
Sebastiaan Velthuis ${ }^{\mathrm{a}}$ Veronique M.M. Vorselaars ${ }^{\mathrm{a}}$ Cornelis J.J. Westermann ${ }^{\mathrm{b}}$ \\ Repke J. Snijder ${ }^{b}$ Johannes J. Mager ${ }^{b}$ Martijn C. Post ${ }^{a}$
}

Departments of a Cardiology and ${ }^{\mathrm{b}}$ Pulmonology, St. Antonius Hospital, Nieuwegein, The Netherlands

\section{Key Words}

Pulmonary right-to-left shunting - Transthoracic contrast echocardiography $\cdot 100 \%$ oxygen method $\cdot$ Hereditary haemorrhagic telangiectasia - Shunt fraction measurement

\begin{abstract}
Background: The presence of pulmonary right-to-left shunting (RLS) is associated with severe neurological complications from paradoxical embolisation in patients with hereditary haemorrhagic telangiectasia (HHT) and screening is warranted. Pulmonary shunt fraction measurement with the $100 \%$ oxygen method can be used for the detection and quantification of functional pulmonary RLS, although transthoracic contrast echocardiography (TTCE) has emerged as the gold standard over the last few years. Objective: The aim of this study was to determine the true diagnostic accuracy of the established $100 \%$ oxygen method in detecting pulmonary RLS, as compared to TTCE. Methods: We analysed 628 persons screened for HHT between 2004 and 2010, all of whom underwent TTCE. A quantitative 3-point grading scale was used to differentiate between minimal, moderate or extensive pulmonary RLS on TTCE (grade 1-3, respectively). Additional shunt fraction measurement with the $100 \%$ oxy-
\end{abstract}

gen method was pursued in cases of $\mathrm{pO}_{2}<13$ or $<12 \mathrm{kPa}$ in patients younger or older than 30 years, respectively. A shunt fraction $>5 \%$ was considered pathological. Results: Both TTCE and the $100 \%$ oxygen method were performed in 210 subjects. Although the presence of a pathological shunt fraction correlated with an increased pulmonary shunt grade on TTCE, the $100 \%$ oxygen method confirmed a $>5 \%$ shunt fraction in only $51 \%$ of patients with pulmonary RLS on TTCE $(14,20$ and $72 \%$ for grade 1, 2 and 3, respectively). Conclusion: Pulmonary shunt fraction measurement with the $100 \%$ oxygen method is not a useful screening technique for the detection of pulmonary RLS in HHT as its sensitivity is too low and large pulmonary shunts on TTCE may remain undetected using this method.

(c) 2015 S. Karger AG, Basel

\section{Introduction}

Pulmonary arteriovenous malformations (PAVMs) are thin-walled abnormal vessels replacing normal capillaries between the pulmonary arterial and venous circulation [1]. A PAVM causes permanent pulmonary right-toleft shunting (RLS), thereby bypassing the pulmonary

\section{KARGER 125}

(c) 2015 S. Karger AG, Base

0025-7931/15/0892-0112\$39.50/0

E-Mail karger@karger.com

www.karger.com/res
S. Velthuis, MD

Department of Cardiology, St. Antonius Hospital Koekoekslaan 1

NL-3435 CM Nieuwegein (The Netherlands)

E-Mail S.Velthuis@antoniusziekenhuis.nl 
capillary filter. Consequently, both emboli of thrombotic and septic origin may directly reach the systemic circulation, causing potential severe neurological complications, such as ischemic strokes or brain abscesses [2]. Gas exchange may also be compromised in the presence of pulmonary RLS, resulting in hypoxaemia and dyspnoea. The majority of PAVMs (70-90\%) are associated with hereditary haemorrhagic telangiectasia (HHT) [3, 4]. HHT is an autosomal dominant inherited disorder, characterised by vascular abnormalities varying from small telangiectasias in skin and mucosal membranes to large arteriovenous malformations, predominantly in the brain, liver and lungs. There are mainly two types of HHT, corresponding with gene mutations coding for endoglin (HHT1) and ALK1 (HHT2) $[5,6]$. Pulmonary RLS has been reported in $91 \%$ of HHT1 and in $53 \%$ of HHT2 patients [7]. Due to this high prevalence coupled with its potential severe complications and the existence of effective treatment options with transcatheter embolotherapy, screening for pulmonary RLS is recommended in all patients with possible or confirmed HHT [8-10]. Pulmonary shunt fraction measurement with the $100 \%$ oxygen method has long been performed as the initial screening technique, based on alveolar-arterial oxygen differences after breathing $100 \%$ oxygen [3], but during the last few years transthoracic contrast echocardiography (TTCE) has evolved as the recommended first-line screening technique for the detection of pulmonary RLS $[9,11]$. However, the $100 \%$ oxygen method has never been directly compared to TTCE and is still in use for the detection and quantification of pulmonary RLS and analysis of unexplained hypoxaemia. Therefore, the present large observational study determined the true diagnostic accuracy of pulmonary shunt fraction measurement with the established $100 \%$ oxygen method in detecting functional pulmonary RLS compared to TTCE as the modern gold standard.

\section{Methods}

\section{Study Population}

Between May 2004 and December 2010, 669 subjects above 15 years of age were screened for HHT in the St. Antonius Hospital, Nieuwegein, The Netherlands. Subjects were screened in a 1-day protocol, as family members of index patients or in case of clinical symptoms suggesting HHT. A complete history and physical examination were performed by a pulmonologist with dedicated expertise in HHT. The clinical diagnosis of HHT was established according to the Curaçao criteria [12]. These criteria consist of spontaneous and recurrent epistaxis, telangiectasias at characteristic sites, visceral arteriovenous malformations and a first-degree relative with HHT. Genetic testing for the HHT-causing gene mutation was offered to all screened subjects and performed as published previously [13]. A definite diagnosis of HHT was established in the case of three or more clinical Curaçao criteria, or when genetic testing identified the HHT-causing mutation. The diagnosis of HHT was 'possible' in patients with two clinical Curaçao criteria without genetic testing or if no mutation had been found in the family. The diagnosis of HHT was 'unlikely' in the presence of less than two clinical Curaçao criteria without genetic testing or if no mutation had been found in the family. HHT was rejected when genetic testing excluded the known HHT-causing family mutation. The study was approved by the institutional review board (LTME/Z-12.41).

\section{Pulmonary Shunt Fraction Measurement with the Established} 100\% Oxygen Method

The arterial partial oxygen pressure $\left(\mathrm{pO}_{2}, \mathrm{kPa}\right)$ was measured at rest, breathing room air in a semi-recumbent position. An additional shunt fraction measurement with the $100 \%$ oxygen method was pursued in cases with a $\mathrm{pO}_{2}<13$ or $<12 \mathrm{kPa}$ in patients younger or older than 30 years, respectively. Patients breathed $100 \%$ oxygen from a Douglas bag, via a closely fitting mouthpiece and two-way valve, while wearing a nose clip and taking a deep inspiration every minute. An arterial blood sample was obtained after breathing $100 \%$ oxygen for $30 \mathrm{~min}$ and the samples were cooled on ice and analysed immediately for oxygen and carbon dioxide tensions. The pulmonary shunt fraction was calculated using the established classical equation: $\mathrm{Q}_{\mathrm{s}} / \mathrm{Q}_{\mathrm{t}}=\left(\mathrm{C}_{\mathrm{c}, \mathrm{O}_{2}}-\mathrm{C}_{\mathrm{a}, \mathrm{O}_{2}}\right) /\left(\mathrm{C}_{\mathrm{c}, \mathrm{O}_{2}}\right.$ $-\mathrm{C}_{\mathrm{v}, \mathrm{O}_{2}}$ ), in which $\mathrm{Q}_{\mathrm{s}} / \mathrm{Q}_{\mathrm{t}}$ is the RLS as a fraction of the cardiac output, $\mathrm{C}_{\mathrm{c}, \mathrm{O}_{2}}$ is the oxygen content at the end of the pulmonary capillary, $\mathrm{C}_{\mathrm{a}, \mathrm{O}_{2}}$ is the oxygen content of arterial blood and $\mathrm{C}_{\mathrm{v}, \mathrm{O}_{2}}$ is the oxygen content of mixed venous blood [14]. The $\mathrm{C}_{\mathrm{v}, \mathrm{O}_{2}}$ was defined as the $\mathrm{C}_{\mathrm{a}, \mathrm{O}_{2}}-4.4 \mathrm{ml} \mathrm{O}_{2} / 100 \mathrm{ml}$ blood [15]. Since the total blood oxygen content is composed of dissolved $\mathrm{O}_{2}$ plus $\mathrm{HbO}_{2}$ and the solubility of oxygen in blood is $0.0225 \mathrm{ml} / 100 \mathrm{ml} / \mathrm{kPa}$, the oxygen content was calculated as follows: oxygen content $\left(\mathrm{ml} \mathrm{O}_{2} / 100 \mathrm{ml}\right.$ blood $)=\left(0.0225 \times \mathrm{pO}_{2}\right)+\left(2.24 \times\right.$ haemoglobin $\left.\times \mathrm{SaO}_{2} / 100\right)$, where $\mathrm{pO}_{2}$ is the partial oxygen pressure $(\mathrm{kPa})$, haemoglobin is expressed in $\mathrm{mmol} / \mathrm{l}$ and $\mathrm{SaO}_{2}$ is the arterial oxygen saturation (\%). The haemoglobin oxygen saturation at the end of the pulmonary capillary is assumed to be $100 \%$. The partial pressure of carbon dioxide $\left(\mathrm{pCO}_{2}\right)$ is assumed to equal the alveolar partial pressure of oxygen $\left(\mathrm{pO}_{2}\right)$ and can be calculated as follows: $\mathrm{pO}_{2}=$ barometric pressure $(101.3 \mathrm{kPa})-\mathrm{pCO}_{2}$ - alveolar saturated water vapour pressure $\left(\mathrm{P}_{\mathrm{A}, \mathrm{H}_{2} \mathrm{O}}\right) \cdot \mathrm{P}_{\mathrm{A}, \mathrm{H}_{2} \mathrm{O}}$ is $6.3 \mathrm{kPa}$ at a body temperature of $37^{\circ} \mathrm{C}$. Using the $100 \%$ oxygen method, a pulmonary shunt fraction of $>5 \%$ was considered pathological $[3,15]$. Patients with previously treated PAVMs were not included in our analysis.

\section{Transthoracic Contrast Echocardiography}

TTCE was performed by placing an intravenous line in the right ante-cubital vein to which two 10 -ml syringes were connected, one filled with an 8-ml physiologic saline solution and the other with $1 \mathrm{ml}$ of air. Subsequently, $1 \mathrm{ml}$ blood was drawn in the airfilled syringe and mixed with the saline-filled syringe by reverse flushing between both syringes, creating agitated saline (microbubbles). The patient was positioned in the left lateral position and $5 \mathrm{ml}$ of fresh agitated saline was injected within $3 \mathrm{~s}$ while projecting the 4-chamber apical view, with and without a Valsalva manoeuvre. TTCE was performed by a constant group of three trained echocardiographers. Interpretation of RLS was performed by two cardiologists with dedicated expertise in both TTCE and HHT, 
Fig. 1. Flow chart of the selected study population.

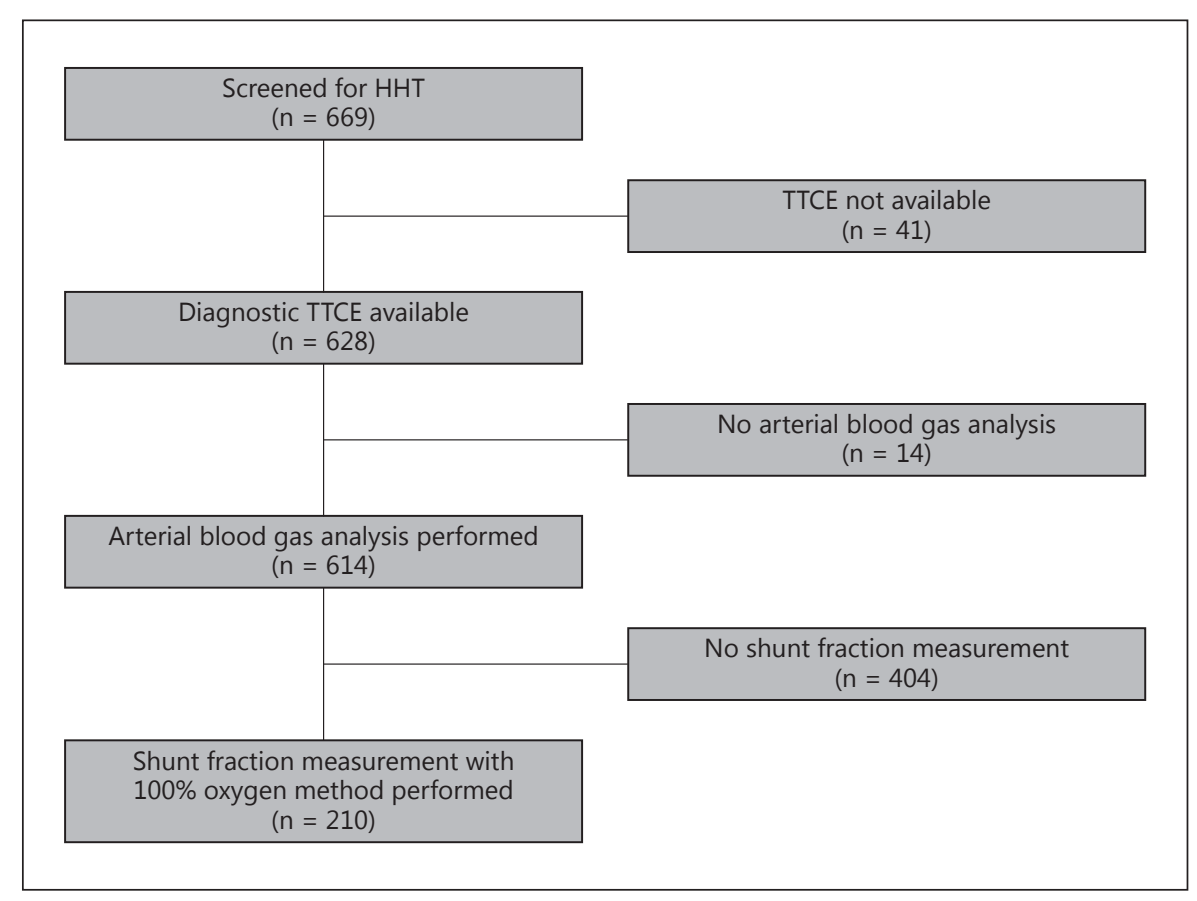

who were unaware of the patients' medical history or prior shunt fraction measurement. In the case of RLS, visualisation of shunt origin was pursued in every TTCE. All RLS visualised through a pulmonary vein was classified as pulmonary RLS. On the occasion of poor visualisation of shunt origin, we used a delay of 4 cardiac cycles to distinguish pulmonary from cardiac RLS, in which TTCE was considered positive for pulmonary RLS if microbubbles appeared in the left atrium after 4 cardiac cycles, as published previously $[11,16,17]$. This delay in the appearance of microbubbles in the left atrium was measured in the number of cardiac cycles after the first appearance of microbubbles in the right atrium. Opacification of the left ventricle was quantitatively graded as 1 (a maximum of 29 microbubbles in the left ventricle), 2 (30-100 microbubbles) or 3 (>100 microbubbles). This division was based on the maximum number of microbubbles in the left ventricle counted in one still frame. A good $\kappa$ coefficient of 0.85 up to 0.94 was found for interobserver agreement concerning this pulmonary shunt grade on TTCE in previous studies $[17,18]$. RLS within 4 cardiac cycles with poor visualisation of shunt origin was classified as indeterminate shunting and excluded from further analysis. A patent foramen ovale was diagnosed only after a positive Valsalva manoeuvre, without spontaneous RLS. The presence of an atrial septum defect was routinely excluded in all RLS using colour Doppler or potential negative contrast in the right atrium [19].

\section{Chest CT}

Chest CT images were routinely obtained on a $16+$ multi-detector CT scanner (Philips Medical Systems), with a dedicated high-resolution algorithm and maximum slice thickness of $1 \mathrm{~mm}$. Identification of PAVMs on chest CT was based on the presence of a nodular opacity with both an afferent and efferent vessel. Chest CT scans were evaluated by two independent observers highly experienced in evaluating PAVMs (a radiologist and a pulmonolo- gist), both blinded to the results from TTCE and shunt fraction measurement. When the observers disagreed, chest CT was considered positive for a PAVM and additional angiography of the pulmonary artery was performed given the impact of potential complications from a missed treatable PAVM.

\section{Statistics}

Descriptive statistics were used to describe patient characteristics. Continuous variables with a normal distribution were presented as the mean \pm standard deviation. A median range was used when normal distribution was absent. Sensitivity, specificity, positive predictive value and negative predictive value with their $95 \%$ confidence intervals (CI), and the area under the receiver operating characteristic (ROC) curve were determined for shunt fraction measurement with the $100 \%$ oxygen method compared to TTCE as the gold standard. Statistical analyses were performed using the statistical software application SPSS (version 17.0; SPSS Inc., Chicago, Ill., USA).

\section{Results}

\section{Study Population}

Out of the 669 individuals screened for HHT, a diagnostic TTCE was available in 628 (93.9\%). Arterial blood gas analysis was performed in 614 out of these 628 subjects (97.8\%). Based on the previous described $\mathrm{pO}_{2}$ values, 210 persons $(34.2 \%)$ underwent additional pulmonary shunt fraction measurement with the $100 \%$ oxygen method and were included for further analysis (fig. 1). Out of 


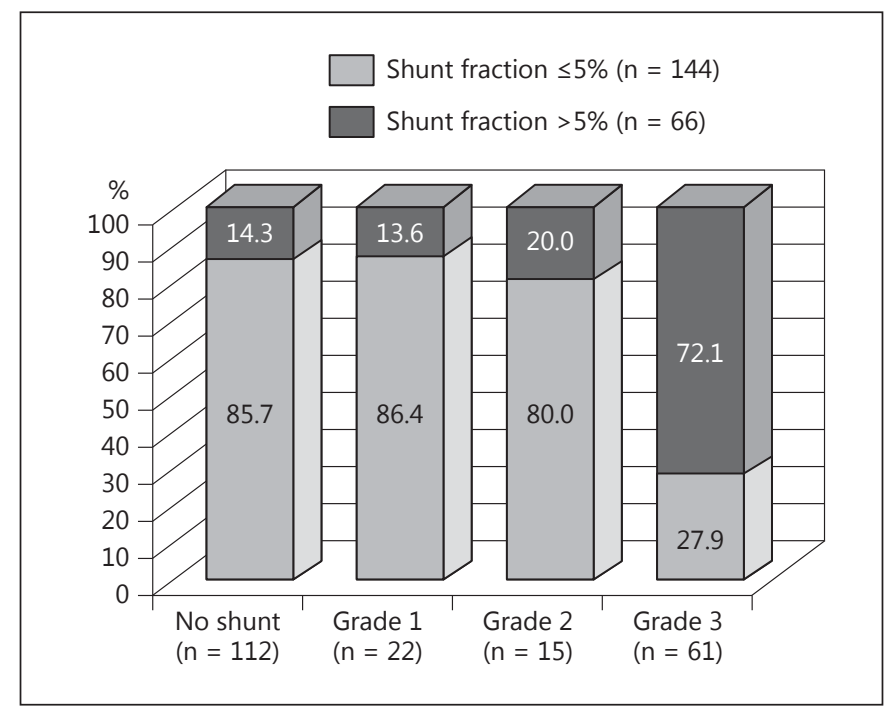

Fig. 2. Pulmonary shunt fraction measurement with the $100 \%$ oxygen method compared to different pulmonary shunt grades on TTCE $(n=210)$.

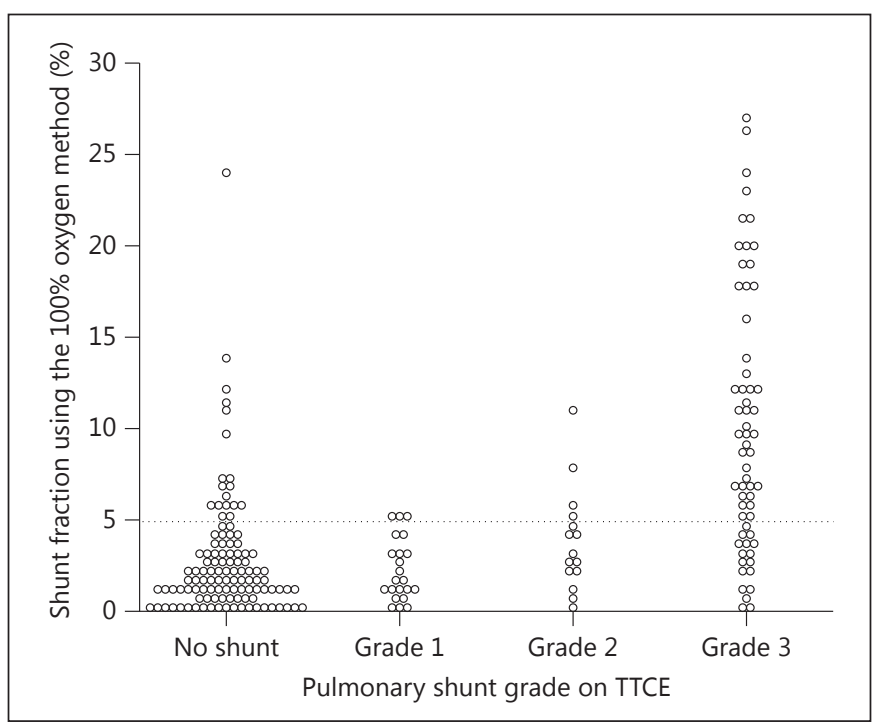

Fig. 3. Dot plot demonstrating the shunt fractions measured with the $100 \%$ oxygen method compared to graded TTCE as the gold standard $(\mathrm{n}=210)$.

these 210 persons, the presence of HHT was definite in 135 patients $(64.3 \%)$, possible in $17(8.1 \%)$, unlikely in 19 $(9.0 \%)$ and excluded in $39(18.6 \%)$. Genetic testing was performed in 188 out of the 210 patients $(89.5 \%)$, which identified 62 (29.5\%) with HHT1 and $62(29.5 \%)$ with HHT2. The baseline characteristics of our final study population are described in table 1.

Time to Abandon the $100 \%$ Oxygen Method in HHT Patients?
Table 1. Baseline characteristics of the study population analysed with both TTCE and the $100 \%$ oxygen method

\begin{tabular}{lc}
\hline Patients & 210 \\
Female & $128(61.0)$ \\
Age, years & $46.8 \pm 15.1$ \\
\hline HHT & \\
Definite & $135(64.3)$ \\
$\quad$ HHT 1 & $62(29.5)$ \\
$\quad$ HHT 2 & $62(29.5)$ \\
Possible & $17(8.1)$ \\
Unlikely & $19(9.0)$ \\
Excluded & $39(18.6)$ \\
\hline Pulmonary shunt on TTCE & \\
Grade 1 & $22(10.5)$ \\
Grade 2 & $15(7.1)$ \\
Grade 3 & $61(29.0)$ \\
No pulmonary shunt on TTCE & $112(53.3)$ \\
PFO & $10(4.8)$ \\
Shunt fraction $\leq 5 \%$ & $144(68.6)$ \\
Shunt fraction $>5 \%$ & $66(31.4)$ \\
\hline PAVM on chest CT & \\
Yes & $66(31.4)$ \\
No & $141(67.1)$ \\
\hline
\end{tabular}

Data are presented as $\mathrm{n}$ with percentages in parentheses, or the mean \pm standard deviation. $\mathrm{PFO}=$ Patent foramen ovale.

\section{Pulmonary Shunt Fraction Measurement with the 100\% Oxygen Method Compared to TTCE}

Pulmonary RLS on TTCE was present in 98 out of the 210 patients $(46.7 \%)$. A pulmonary shunt grade 1 was diagnosed in 22 patients $(22.4 \%)$, grade 2 in $15(15.3 \%)$ and grade 3 in 61 (62.2\%). The 100\% oxygen method documented a pathological shunt fraction of $>5 \%$ in 13.6, 20.0 and $72.1 \%$ of the patients with a pulmonary shunt grade 1,2 or 3 on TTCE, respectively (fig. 2). The mean pulmonary shunt fraction in patients with pulmonary shunt grades 1,2 and 3 on TTCE was 2.2, 3.8 and $10.1 \%$, respectively (fig. 3). Using TTCE as the gold standard for the detection of functional pulmonary RLS, the 100\% oxygen method had a sensitivity of $51 \%$ (95\% CI $0.41-0.61)$ and a specificity of $86 \%$ ( $95 \%$ CI $0.78-0.91$; table $2 a)$, with an area under the ROC curve of 0.74 (95\% CI 0.67-0.81). The diagnostic accuracy of the $100 \%$ oxygen method in detecting only moderate to large pulmonary shunts on TTCE (grades 2 and 3) slightly increased to a sensitivity of $62 \%(95 \%$ CI $0.51-0.72)$ and a specificity of $86 \%(95 \%$ CI $0.79-0.9$; table $2 \mathrm{~b}$ ), with an area under the ROC curve of 0.82 (95\% CI $0.75-0.88)$. 
Table 2. Pulmonary shunt fraction measurement using the $100 \%$ oxygen method compared to TTCE a Diagnostic accuracy of the $100 \%$ oxygen method in detecting any pulmonary RLS on TTCE

\begin{tabular}{lccr}
\hline & Shunt fraction $\leq 5 \%$ & Shunt fraction $>5 \%$ & Total \\
\hline No pulmonary shunt on TTCE & 96 & 16 & 112 \\
Any pulmonary shunt on TTCE & 48 & 50 & 98 \\
Total & 144 & 66 & 210 \\
\hline
\end{tabular}

Sensitivity $51 \%(0.41-0.61)$, specificity $86 \%$ (95\% CI $0.78-0.91)$, positive predictive value $76 \%$ (95\% CI 0.64 -0.84 ), negative predictive value $67 \%$ (95\% CI $0.58-0.74)$.

b Diagnostic accuracy of the $100 \%$ oxygen method in detecting only pulmonary shunt grades 2 and 3 on TTCE

\begin{tabular}{lccr}
\hline & Shunt fraction $\leq 5 \%$ & Shunt fraction $>5 \%$ & Total \\
\hline No or grade 1 pulmonary shunt on TTCE & 115 & 19 & 134 \\
Only pulmonary shunt grade 2 or 3 on TTCE & 29 & 47 & 76 \\
Total & 144 & 66 & 210 \\
\hline
\end{tabular}

Sensitivity $62 \%$ ( $95 \%$ CI $0.51-0.72$ ), specificity $86 \%$ (95\% CI $0.79-0.9)$, positive predictive value $71 \%$ ( $95 \%$ CI $0.59-0.81)$, negative predictive value $80 \%$ (95\% CI $0.73-0.86$ ).

The $100 \%$ oxygen method revealed a pathological shunt fraction of $>5 \%$ in $14.3 \%$ of subjects without any RLS on TTCE. A mean shunt fraction of $9.1 \%$ was found in these false-positive cases. Chest CT demonstrated regions with atelectasis and/or pulmonary fibrosis in $53.3 \%$ of these persons, but no alternative explanation was found in the other $46.7 \%$ of false-positive cases.

TTCE showed a patent foramen ovale in 10 out of the 210 patients $(4.8 \%)$, where the $100 \%$ oxygen method revealed a pathological shunt fraction of $>5 \%$ in only 3 of these patients. No atrial septum defect was documented.

Chest CT was performed in 207 out of the 210 patients (98.6\%) with both TTCE and shunt fraction measurement. Although already selected by a lower $\mathrm{pO}_{2}$, chest CT confirmed the presence of PAVMs in 66 out of 98 patients (67.3\%) with pulmonary RLS on TTCE. Pulmonary shunt fraction measurement with the $100 \%$ oxygen method identified a pathological shunt fraction in 46 out of 66 patients with a PAVM on chest CT (69.7\%). The $100 \%$ oxygen method did not reveal an abnormal shunt fraction in the other $41.7 \%$ of patients with visible PAVMs on chest CT.

\section{Discussion}

To our knowledge, this is the first large study evaluating the true diagnostic accuracy of pulmonary shunt fraction measurement with the $100 \%$ oxygen method in detecting functional pulmonary RLS compared to TTCE as the modern gold standard. Our results firmly indicate that pulmonary shunt fraction measurement with the $100 \%$ oxygen method is not a reliable test to screen for PAVMs in patients with HHT.

Screening for PAVMs is warranted in all patients with possible or confirmed HHT, given the high risk of neurological complications that may be prevented by transcatheter embolotherapy. Arterial blood gas analysis and additional pulmonary shunt fraction measurement with the $100 \%$ oxygen method have been used as non-invasive screening tests for the detection of functional pulmonary RLS in these subjects. Under normal conditions, the fraction of cardiac output that shunts from right-to-left (i.e. the shunt fraction) is $\leq 5 \%$. A pathological shunt fraction of $>5 \%$ has been reported in up to $97.5 \%$ of patients with PAVMs prior to transcatheter embolotherapy [20-25] and the $100 \%$ oxygen method has long been assumed to be accurate enough for the detection of clinically important pulmonary RLS. However, a retrospective study of 105 individuals screened for HHT by Cottin et al. [26] previously suggested a markedly lower sensitivity (up to 68\%) of the $100 \%$ oxygen method in detecting pulmonary RLS compared to anatomical-based tests like chest CT and pulmonary angiography. Over the last few years, TTCE has evolved as the first-line screening technique for the detection of functional pulmonary RLS based on its excellent sensitivity, high negative predictive value and wide availability with low risks and costs $[9,11,17,27-29]$. However, studies directly comparing the $100 \%$ oxygen method
Velthuis/Vorselaars/Westermann/ Snijder/Mager/Post 
to TTCE are lacking. The current analysis was warranted to reveal the true diagnostic accuracy of pulmonary shunt fraction measurement with the $100 \%$ oxygen method as we know that chest CT confirms the presence of PAVMs in only $45 \%$ of patients with pulmonary RLS on TTCE [7]. The present study demonstrates that the $100 \%$ oxygen method detects a pathological shunt fraction of $>5 \%$ in only $51 \%$ of patients with any pulmonary RLS on TTCE. The majority of patients with a pulmonary shunt grade 1 or 2 on TTCE remain undetected using the $100 \%$ oxygen method ( 86.4 and $80.0 \%$, respectively). Even in patients with a large, pulmonary shunt grade 3 on TTCE, the $100 \%$ oxygen method fails to detect an abnormal shunt fraction in $27.9 \%$ of cases. Our group recently described that only pulmonary shunt grades 2 and 3 on TTCE have clinical implications $[2,7,30]$, as neurological complications due to paradoxical embolisations are encountered in up to $14.2 \%$ of these shunts [2] and transcatheter embolotherapy of PAVMs is indicated in $52.5 \%$ of these patients [7]. However, the present study reveals that the $100 \%$ oxygen method fails to detect a pathological shunt fraction of $>5 \%$ in $38.2 \%$ of patients with a pulmonary shunt grade 2 or 3 on TTCE. Furthermore, the current international guideline on the diagnosis and management of HHT recommends the use of antibiotic prophylaxis before procedures with risk of bacteraemia in patients with any documented pulmonary RLS in order to prevent the occurrence of brain abscesses [9]. The current study illustrates that up to $49 \%$ of these patients will not be identified using shunt fraction measurements with the 100\% oxygen method.

On the other hand, we documented a pathological shunt fraction of $>5 \%$ in $14.3 \%$ of individuals without any RLS on TTCE. Additional chest CT imaging showed regions with atelectasis and/or pulmonary fibrosis in $53.3 \%$ of these persons, but no alternative explanation for the increased shunt fraction was found in the remaining $46.7 \%$ (true false positives). Besides the fact that a small degree of physiologic RLS normally takes place via the bronchiolar system of the lung perfusion and Thebesian veins, there may be several sources of error resulting in false-positive or negative findings with the $100 \%$ oxygen method. The detection of pulmonary RLS using TTCE is based on the true anatomical and functional shunt, while the $100 \%$ oxygen method measures the alveolar-arterial oxygen difference, which is then converted into a shunt magnitude. The $100 \%$ oxygen method will be influenced by the presence of multiple small PAVMs, where oxygen uptake may still take place and the actual RLS is underestimated. Furthermore, the arteriovenous difference in oxygen content is not routinely measured in the established $100 \%$ oxygen method and devia- tions from the assumed value could therefore result in deviations from the calculated shunt fraction. Measurement of the actual individual arteriovenous difference would improve the accuracy of the $100 \%$ oxygen method, but is not feasible in daily practice because of its invasive character. In addition, an accurate test can only be obtained when the patient truly receives $100 \%$ oxygen. A small leak in the oxygen delivery system will overestimate the degree of shunt fraction by lowering the true alveolar partial oxygen pressure. Similarly, breathing $100 \%$ oxygen for an inadequate period of time may result in an overestimation of the shunt fraction, owing to inadequate denitrogenation of poorly ventilated alveoli (which was not the case in the present study). It has also been reported that breathing $100 \%$ oxygen can occasionally cause a small amount of pulmonary RLS (up to 11\%) in healthy subjects, due to complete denitrogenation and micro-atelectasis [31]. Taking a deep inspiration every minute helps to prevent this $100 \%$ oxygenrelated micro-atelectasis [20]. Further study limitations are the fact that additional shunt fraction measurement was not routinely performed in all 669 screened persons and that the $100 \%$ oxygen method was tested in a population at high pre-test risk for PAVMs (HHT). Therefore, our results do not automatically support generalisation to all other aetiologies of pulmonary shunting.

\section{Conclusion}

Pulmonary shunt fraction measurement with the $100 \%$ oxygen method is not a useful screening technique for the detection of pulmonary RLS in HHT. The reasons for this are that its sensitivity is too low and a large proportion of clinically important pulmonary RLS remains undetected.

\footnotetext{
References $\nabla_{1}$ Begbie ME, Wallace GM, Shovlin CL: Hereditary haemorrhagic telangiectasia (Osler-Weber-Rendu syndrome): a view from the $21 \mathrm{st}$ century. Postgrad Med J 2003;79:18-24.

-2 Velthuis S, Buscarini E, van Gent MW, Gazzaniga P, Manfredi G, Danesino C, et al: Grade of pulmonary right-to-left shunt on contrast echocardiography and cerebral complications: a striking association. Chest 2013; 144:542-548.

3 Gossage JR, Kanj G: Pulmonary arteriovenous malformations: a state of the art review. Am J Respir Crit Care Med 1998;158:643-661.

4 Mager JJ, Overtoom TT, Blauw H, Lammers JW, Westermann CJ: Embolotherapy of pulmonary arteriovenous malformations: longterm results in 112 patients. J Vasc Interv Radiol 2004; 15:451-456.
}

Time to Abandon the 100\% Oxygen Method in HHT Patients? 
-5 Berg JN, Gallione CJ, Stenzel TT, Johnson DW, Allen WP, Schwartz CE, et al: The activin receptor-like kinase 1 gene: genomic structure and mutations in hereditary hemorrhagic telangiectasia type 2. Am J Hum Genet 1997;61:60-67.

-6 McAllister KA, Grogg KM, Johnson DW, Gallione CJ, Baldwin MA, Jackson CE, et al: Endoglin, a TGF- $\beta$ binding protein of endothelial cells, is the gene for hereditary haemorrhagic telangiectasia type 1 . Nat Genet 1994; 8:345-351.

7 Velthuis S, Buscarini E, Mager JJ, Vorselaars VM, van Gent MW, Gazzaniga P, et al: Predicting the size of pulmonary arteriovenous malformations on chest computed tomography: a role for transthoracic contrast echocardiography. Eur Respir J 2014;44:150-159.

8 Cottin V, Dupuis-Girod S, Lesca G, Cordier JF: Pulmonary vascular manifestations of hereditary hemorrhagic telangiectasia (RenduOsler disease). Respiration 2007;74:361-378.

-9 Faughnan ME, Palda VA, Garcia-Tsao G, Geisthoff UW, McDonald J, Proctor DD, et al: International guidelines for the diagnosis and management of hereditary haemorrhagic telangiectasia. J Med Genet 2011;48:73-87.

10 Gallitelli M, Guastamacchia E, Resta F, Guanti G, Sabba C: Pulmonary arteriovenous malformations, hereditary hemorrhagic telangiectasia, and brain abscess. Respiration 2006; 73:553-557.

11 van Gent MW, Post MC, Luermans JG, Snijder RJ, Westermann CJ, Plokker HW, et al: Screening for pulmonary arteriovenous malformations using transthoracic contrast echocardiography: a prospective study. Eur Respir J 2009;33:85-91.

-12 Shovlin CL, Guttmacher AE, Buscarini E, Faughnan ME, Hyland RH, Westermann CJ, et al: Diagnostic criteria for hereditary hemorrhagic telangiectasia (Rendu-Osler-Weber syndrome). Am J Med Genet 2000;91:66-67.

13 Letteboer TG, Zewald RA, Kamping EJ, de Haas G, Mager JJ, Snijder RJ, et al: Hereditary hemorrhagic telangiectasia: ENG and ALK-1 mutations in Dutch patients. Hum Genet 2005;116:8-16.
14 Chiang ST: Anomogram for venous shunt (Qs-Qt) calculation. Thorax 1968;23:563565.

15 Mager JJ, Zanen P, Verzijlbergen F, Westermann CJ, Haitjema T, van Herk G, et al: Quantification of right-to-left shunt with ${ }^{99 \mathrm{~m}} \mathrm{Tc}$-labelled albumin macroaggregates and $100 \%$ oxygen in patients with hereditary haemorrhagic telangiectasia. Clin Sci (Lond) 2002;102:127-134.

16 van Gent MW, Post MC, Snijder RJ, Swaans MJ, Plokker HW, Westermann CJ, et al: Grading of pulmonary right-to-left shunt with transthoracic contrast echocardiography: does it predict the indication for embolotherapy? Chest 2009;135:1288-1292.

17 van Gent MW, Post MC, Snijder RJ, Westermann CJ, Plokker HW, Mager JJ: Real prevalence of pulmonary right-to-left shunt according to genotype in patients with hereditary hemorrhagic telangiectasia: a transthoracic contrast echocardiography study. Chest 2010;138:833-839.

$>18$ Gazzaniga P, Buscarini E, Leandro G, Reduzzi L, Grosso M, Pongiglione G, et al: Contrast echocardiography for pulmonary arteriovenous malformations screening: does any bubble matter? Eur J Echocardiogr 2009;10:513518.

19 Soliman OI, Geleijnse ML, Meijboom FJ, Nemes A, Kamp O, Nihoyannopoulos P, et al: The use of contrast echocardiography for the detection of cardiac shunts. Eur J Echocardiogr 2007;8:S2-S12.

20 Chilvers ER, Whyte MK, Jackson JE, Allison DJ, Hughes JM: Effect of percutaneous transcatheter embolization on pulmonary function, right-to-left shunt, and arterial oxygenation in patients with pulmonary arteriovenous malformations. Am Rev Respir Dis 1990;142:420-425.

-21 Haitjema TJ, Overtoom TT, Westermann CJ, Lammers JW: Embolisation of pulmonary arteriovenous malformations: results and follow up in 32 patients. Thorax 1995;50:719723.
22 Hartnell GG, Jackson JE, Allison DJ: Coil embolization of pulmonary arteriovenous malformations. Cardiovasc Intervent Radiol 1990;13:347-350.

23 Jackson JE, Whyte MK, Allison DJ, Hughes JM: Coil embolization of pulmonary arteriovenous malformations. Cor Vasa 1990;32: 191-196.

24 Pennington DW, Gold WM, Gordon RL, Steiger D, Ring EJ, Golden JA: Treatment of pulmonary arteriovenous malformations by therapeutic embolization: rest and exercise physiology in eight patients. Am Rev Respir Dis 1992;145:1047-1051.

25 Terry PB, White RIJ, Barth KH, Kaufman SL, Mitchell SE: Pulmonary arteriovenous malformations: physiologic observations and results of therapeutic balloon embolization. N Engl J Med 1983;308:1197-1200.

26 Cottin V, Plauchu H, Bayle JY, Barthelet M, Revel D, Cordier JF: Pulmonary arteriovenous malformations in patients with hereditary hemorrhagic telangiectasia. Am J Respir Crit Care Med 2004;169:994-1000.

27 Bommer WJ, Shah PM, Allen H, Meltzer R, Kisslo J: The safety of contrast echocardiography: report of the Committee on Contrast Echocardiography for the American Society of Echocardiography. J Am Coll Cardiol 1984; $3: 6-13$.

28 Gossage JR: The role of echocardiography in screening for pulmonary arteriovenous malformations. Chest 2003;123:320-322.

29 Nanthakumar K, Graham AT, Robinson TI, Grande P, Pugash RA, Clarke JA, et al: Contrast echocardiography for detection of pulmonary arteriovenous malformations. Am Heart J 2001;141:243-246.

30 Velthuis S, Vorselaars VM, van Gent MW, Westermann CJ, Snijder RJ, Mager JJ, et al: Role of transthoracic contrast echocardiography in the clinical diagnosis of hereditary hemorrhagic telangiectasia. Chest 2013;144: 1876-1882.

31 Wagner PD, Laravuso RB, Uhl RR, West JB: Continuous distributions of ventilation-perfusion ratios in normal subjects breathing air and 100 per cent $\mathrm{O}_{2}$. J Clin Invest 1974;54: 54-68. 